\title{
Characterization methods of amorphous form stability in solid dispersion: A review
}

\author{
Maria Elvina Tresia Butarbutar ${ }^{1, *}$, Nasrul Wathoni ${ }^{2}$, Yoga Windhu Wardhana ${ }^{1}$ \\ ${ }^{1}$ Magister Program of Pharmacy, Faculty of Pharmacy, Universitas Padjadjaran, Jatinangor 45363, \\ Indonesia. \\ ${ }^{2}$ Departement of Pharmaceutics and Pharmaceutical Technology, Universitas Padjadjaran, Jatinangor 45363
}

Received : 2 May 2020/Revised : 12 May 2020/Accepted : 17 May 2020/ Published:23 Jun 2020

\begin{abstract}
Solubility as a cause of ineffective active pharmaceutical ingredients (API) needs to be a concern. One of the solutions to increase the solubility by choosing active ingredients in the amorphous form. However, the amorphous form tends to be unstable because it has high Gibbs free energy and molecular mobility. To overcome those properties solid dispersion methods can be an answer. The dispersion of the amorphous form in the polymer is expected to prevent the transformation of API to crystal stable form. The solid dispersion (SD) resulted needs for physicochemical characterization to prove the ability of SD to maintain the amorphous form. Therefore, the physicochemical properties of the amorphous solid dispersions (ASDs) have to analyze there in any interactions that are able to occur between the drug and the polymer. Also for evaluate the stability of the ASDs within a certain period. In the article presents, some articles related with ASDs and its characterization will studying, include several product on the market as example. The number of literature used in this article is 69 articles.
\end{abstract}

Keywords: Solubility, amorphous for, solid dispersion, characterization ASDs.

\begin{abstract}
Abbreviations
DSC - Differential scanning calorimetry

FTIR - Fourier transform infrared

HSPLM - Hot stage polarization light microscopy

PLM - Polarization light microscopy

SEM - Scanning electron microscopy

SsNMR - Solid state nuclear magnetic resonance

TGA - Thermogravimetric analysis

TMDSC - Temperature modulated differential scanning calorimetry
\end{abstract}

\section{Introduction}

More than $75 \%$ of commercial pharmaceutical oral solid dosage forms have poor water solubility (1). This properties will affect the availability of biological and therapeutic activities. Several factors that affect solubility of the API which, polymorphism (2), crystallinity (3), particle size (4),
$\mathrm{pKa}$ (1), dielectric constant, and polarity (5). One effort to improve API solubility is choosing an amorphous forms which has better solubility than a stable crystalline form (3). This amorphous form properties come from lacks lattice energy, random molecular structure, and large surface area. Besides that, the amorphous form is unstable and tends to 
undergo a molecular transformation in its crystalline stable form. The instability occurs due to high Gibbs free energy and large molecular mobility (6). The strengths and weaknesses of the amorphous form characterize become a solution and also a challenge for the pharmaceutical development.

To overcome this challenge there are methods that are widely used to improve amorphous stability. Solid dispersion is one of the methods, with several techniques, including fusion methods, solvent methods, hot melt extraction, spray drying, freeze drying, supercritical fluid, electrostatic spinning, and lyophillization (6). In solid dispersion methods polymer is generally use as a matrix. The polymer has capable inhibit the bonds orientation between intramolecules and to detain nucleation. In addition, the hydrophilic polymer is also able to improve wettability (7). Characteristics of polymer that can be used as matrix, among others thermal stability at melting temperature, melting point not much higher than that of drug, low vapour pressure, hight molecule weight, and thet should be non toxic (8).
In 2007 to 2017 the Food and Drug and Administration (FDA) has been commercially allowed amorphous solid dispersion (ASD) products (9). Several examples of commercial ASDs products, namely Novir ${ }^{\circledR}$ with Ritonavir as API and using polyvinylpyrolidone (PVP) as a polymer (10). Heterogeneous ASDs are give rise to interactions between drug molecules and polymers that the alter kinetic stability of the drug. In this article presents several aspects regarding ASDs, namely amorphous instability, schematic conversion of API crystalline form from amorphous in solid dispersion systems, characterization of ASDs, and example of ASDs product that have been circulating in the market.

\section{Methodology}

This review is based on the literature obtained from the at Google Scholar, Sciendirect database 2010 - 2019 using the keywords "Amorphous solid dispersion" and "Solid dispersion" and "Characterization amorphous solid dispersion" and "Amorphous form" and "Development of solid dispersion" and "evaluation of solid dispersion".

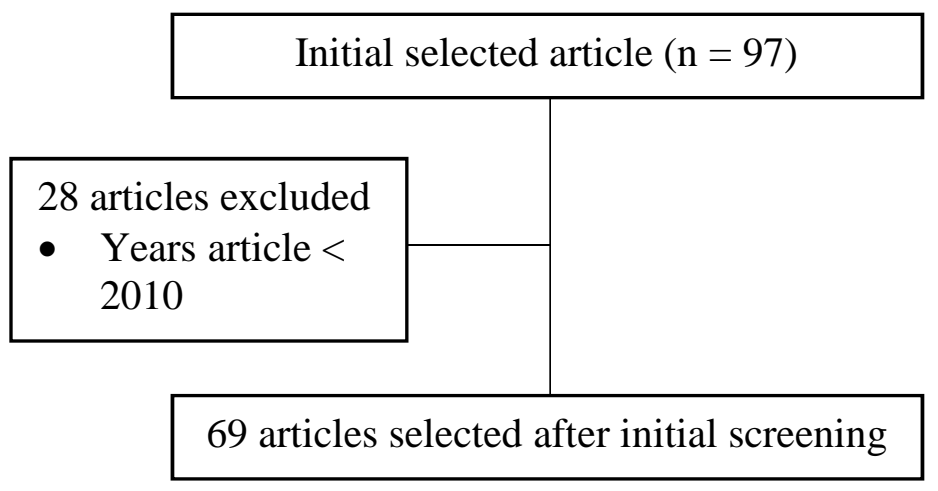

Figure 1. Flow chart of the reference search

\section{Discussion}

\subsection{Amorphous solid dispersion}

Solid dispersions embed active pharmaceutical ingredients (APIs) in polymeric carriers to improve their solubility. Generally, in solid dispersion systems, a highly hydrophilic polymer is used to increase the solubility of API, high $T_{\mathrm{g}}$ than Tg API to maintain API stability of API molecules, high fragility, and hydrogen donors / acceptors because can helped inhibit crystallization. In addition, the thermal characteristics and molecular weight of a polymer will affect the effectiveness of the polymer as a stabilizer (11). The properties of the polymer stabilizer in ASDs are also due to the increase in $T_{\mathrm{g}}$ which causes decreased molecular mobility and increased stability (7). Implement this mechanism have shown the success of increased solubility and stability of the drug in such established products (12-14). 


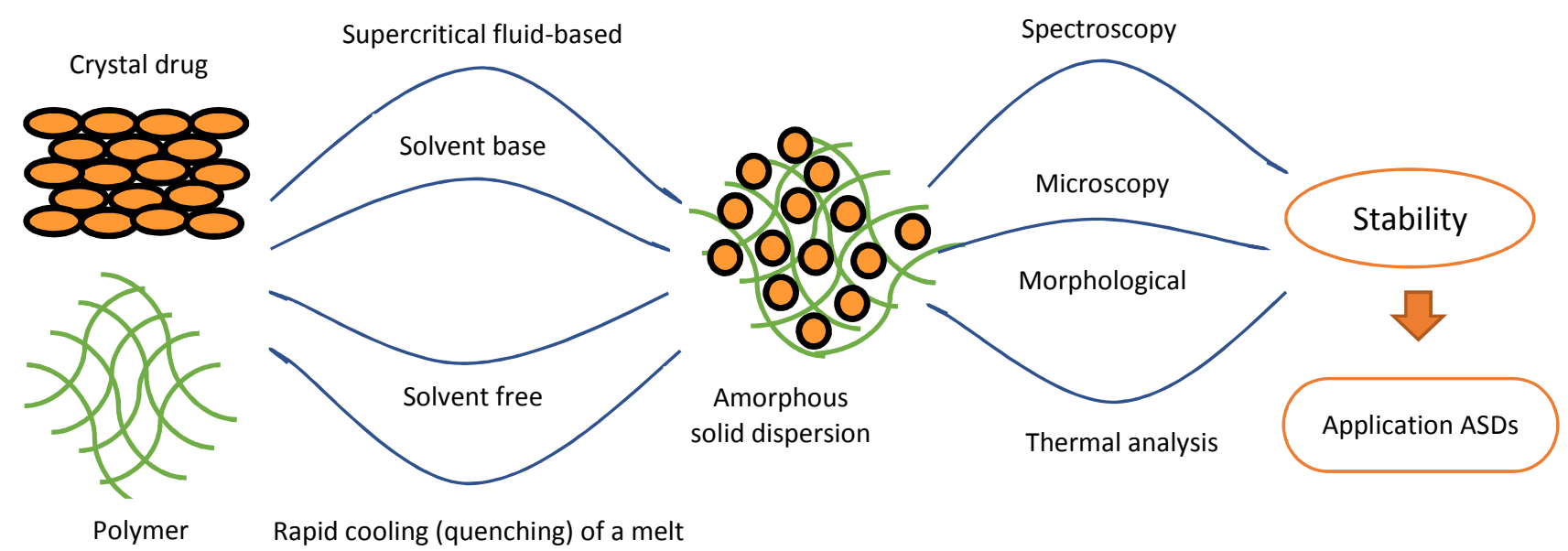

Figure 2. Schematic crystalline drug which becomes an ASDs and is characterized (15)

As demonstrated in Figure 2, molecular interactions occur due the mixing of API and polymer in a completely soluble state. A soluble API will form smaller particles that immediately suspended into a polymer solution producing a heterogeneous (16). The preparation-based on the characteristic of API material. Well known characteristic of API are essential to achieve successful ASDs. For example, the spray drying preparation is used for API that are soluble in volatile solvents (17), a co-precipitation method is used for API with high melting points and low solubility in organic solvents. For API with high melting points, the hot melt extrusion is used instead (18), solvent evaporation method is used for drugs that are unstable to heating drug and carrier are mixed by a solvent instead of heat as in melting method (19). Polymer applications and solid dispersion preparation methods are presented in Table 1.

Based on Table 1, the hot melt extrusion preparation is the most widely used method. The absence of organic solvent yields a result without residue. This method involves mixing, melting, and homogenizing which can be applied on an industrial scale. For example, oleanolic acid prepared using hot melt extrusion using PVP VA64, shows a dissolution rate of $90 \%$ in 10 minutes (18). Also, efavirenz which was also prepared using hot melt extrusion using Plasdone S-630 showed an increase in dissolution rate of 1.7 fold (12).

Because ASDs are molecular, characterization methods are needed to investigate the amorphous form. Several methods are required to complete the amorphous form information in solid dispersions. Characterization methods that can be performed such as thermal analysis (DSC, TMDSC, TGA) to analyze changes in the thermal properties of components, vibrational spectroscopy (FTIR, Raman) to analyze the interaction of component molecules, and XRD to analyze changes in crystallinity as presented in Table 2. The characterization method used in ASDs. Each characterization method will support each other to aid the investigation of amorphous forms in solid dispersions. The next section will discuss the interpretation of result of characterization.

\subsection{Characterization of Amorphous by Solid Dispersion and Applications}

\subsubsection{Spectroscopic Vibrational}

Spectroscopy is a tool often used to investigate interactions between drugs and polymers in solid 
Table 1. Example of different polymers and technique used in the formulation ASDs

\begin{tabular}{|c|c|c|c|c|c|}
\hline API & $\begin{array}{l}\text { BCS } \\
\text { class }\end{array}$ & Polymers / Carrier & $\begin{array}{l}\text { Preparations } \\
\text { method }\end{array}$ & Year & Ref \\
\hline Amphotericin B & IV & Poly-cyclodextrin & Spray drying & 2018 & (20) \\
\hline Baicalin & & $\begin{array}{l}\text { Hydroxypropyl- } \beta- \\
\text { Cyclodextrin } \\
\text { Eudragit }^{\circledR}, \text { Soluplus } \\
{ }^{\circledR},\end{array}$ & $\begin{array}{l}\text { Supercritical fluid } \\
\text { encapsulation }\end{array}$ & 2018 & (21) \\
\hline Carvedilol & II & HPMCAS & Supercritical CO & 2019 & (22) \\
\hline Efavirenz & II & Eudragit EPO, Plasdone S-630 & Hot Melt Extrusion & 2012 & (12) \\
\hline Felodipine & II & Soluplus ${ }^{\circledR}$ & $\begin{array}{l}\text { Hot Melt Extrusion } \\
\text { Melt-quench }\end{array}$ & 2016 & (23) \\
\hline Griseofulvin & II & Kollidone ${ }^{\circledR}$ VA64 & method & 2019 & (24) \\
\hline Hydrocortison & II & PEG 4000, Kolliphor ${ }^{\circledR}$ P-407 & Spray c & 2019 & (25) \\
\hline Ibuprofen & II & HPMCAS, HPMCP HP-55 & Electrospinning & 2019 & (26) \\
\hline Nilotinib & II & $\begin{array}{l}\text { Soluplus }{ }^{\circledR} \\
\text { Kollidon }^{\circledR} \text { VA64, Kollidon } \\
\\
\quad 12 \text { PF, Kollidon }\end{array}$ & Spray dried & 2017 & (14) \\
\hline Nifec & II & Kollidon ${ }^{\circledR} 90 \mathrm{~F}$ & Hot Melt E & 2019 & (15) \\
\hline Oleanolid acid & IV & $\begin{array}{l}\text { PVP VA64 } \\
\text { PVP K-25, PEG 6000, }\end{array}$ & Hot Melt Extrusion & 2017 & (13) \\
\hline Pyrimethamine & III & Poloxamer 188 & Solvent evaporation & 2018 & (27) \\
\hline Ritonavir & IV & PVPVA64 & $\begin{array}{l}\text { Solvent evaporation } \\
\text { Solvent evaporation }\end{array}$ & 2019 & (28) \\
\hline Zoplicone & II & PVP K-25 & / Freeze drying & 2015 & (29) \\
\hline
\end{tabular}

dispersion systems. Changes that occur, such as wavelengths $1231 \mathrm{~cm}^{-1}$ and $1721 \mathrm{~cm}^{-1}$. In the vibrations, homomolecular, and heteromolecular transitions. This method involves electromagnetic waves that interact with materials and cause a transition between vibrations with the energy of the molecule. Spectroscopy can provide information from macro, micro, and nano scales (30). The data gathered in the form of a spectrum that describes the intensity of transmission.

\section{FTIR and Raman}

FTIR $\left(4000-400 \mathrm{~cm}^{-1}\right)$ and Raman $(4000-150$ $\mathrm{cm}^{-1}$ ) are very efficient techniques among the methods of vibration spectroscopy. FTIR can analyze ASDs, which correlate with molecular structure and donor-acceptor characteristics that form hydrogen bonds between drugs and polymers and establish miscibility (31). In addition, FTIR can also conclude the formation of ASDs. ASDs ibuprofen-HPMCAS (1:9) products peak expansion which signifies amorphous presence of ibuprofen at spectrum that describes the amorphous form, wavelength stretching occurs at $1231 \mathrm{~cm}^{-1}$ and 1721 $\mathrm{cm}^{-1}$ which signifies a shift in the carboxyl group, illustrating the presence of hydrogen bonds between carboxylic acids from ibuprofen and hydroxyl groups from HPMCAS (26). Raman on the other hand, is an innovative molecular analysis to evaluate ASDs. The Raman is more sensitive and has a wider spectrum. The spectrum difference between ASDs and crystalline nitredipin can be seen clearly on Raman. Li et al. explains the significant difference in wavelength intensity between nitredipine and nitredipine-PVP crystals. Nitredipine crystals show sharper wavelength than ASDs products. This is supported by the shifting of the C-O-C band at wavelengths of 1680 and $1700 \mathrm{~cm}^{-1}$ which indicates the formation of hydrogen bonds from nitrendipinePVP and confirms the amorphous state (32). These results showed that both FTIR and Raman provided clear information in analyzing ASDs. 


\section{SSNMR}

ssNMR is a non-destructive technique, providing information both qualitatively and quantitatively, it can also be 1-dimensional or 2-dimensional with details based on spectroscopic techniques, relaxometry, and structural images (33). Its main purpose is to identify the structure and transformation of solids. The prediction made by ssNMR regarding the domain size between the drug and the polymer by correlating the relaxation time with the round diffusion length scale (34).

Foster et al., comparing Nifedipine and indomethacin ASDs mobility using ${ }^{1} \mathrm{H}$ NMR. The relaxation behaviour of nifedipine ASDs significantly in comparison compared to indomethacin ASDs that explain that the stability of ASDs nifedipine is lower. However, molecular mobility is not the only parameter to predict nucleation and the rate of crystal growth (35). Skiba et al. uses ${ }^{13} \mathrm{C}$ NMR against cyclosporine ASDs $\alpha \beta$-Cyclodextrins, cyclosporine crystal spectrum with alkyl C-C peak chemical intensity between 30 and $10, \mathrm{~N}-\mathrm{C}=\mathrm{O}$ at $174-170 ; \mathrm{C}=\mathrm{O}$ at $130-120$; $\mathrm{C}-\mathrm{OH}$ at $75-70$; and $\mathrm{N}$ at $60-50 \mathrm{ppm}$ were changed after being on a solid dispersion system. C$\mathrm{C}$ alkyl intensity significantly changes with the occurrence of chemical shifts. It signifies the interaction of cyclosporine- $\alpha \beta$-cyclodextrins converted into an amorphous form (36). Note that the mixing method also affects ssNMR spectrum results.

\subsubsection{Microscopic and Morphological}

Microscopes are widely used for characterization of solids. Information obtained includes morphology, particle size and crystallinity of the sample (37). Characterization of ASDs generally uses polarized light microscopy (PLM) because it can detect crystals or amorphous. Amorphous solids are isotropic, which means the molecules are randomly oriented. As a result, amorphous solids do not have double refraction, are nonbirefringent, and do not show color interference. Meanwhile, crystalline solids are anisoptric whose molecules are arranged in a regular order, have color interference to detect based on the birefringence. In addition, hot stage polarized microscopy (HSPLM) is also widely used in the pharmaceutical field, except that HSPLM can observe the thermal behavior of a sample. The heating and cooling rates can be controlled with accurate results (38).

\section{PLM and HSPLM}

The PLM application was carried out by Kim et al. by the lightly grinding method, which is between dutasteride-polymer $\quad\left(\right.$ Kollicoat $^{\circledR}$ MAE 100P, Soluplus $^{\circledR}$, Lutrol $^{\circledR}$ F68, and Kollidon ${ }^{\circledR}$ K30. Microscopic observations were made to see the solubility of the dutasteride dispersed in a polymer (Fig. 3). It was assumed that the higher the sample clarity from the PLM results then it also had the higher solubility capacity. Based on PLM results, dutasteride - Kollicoat ${ }^{\circledR}$ MAE 100P had a higher solubility (39).

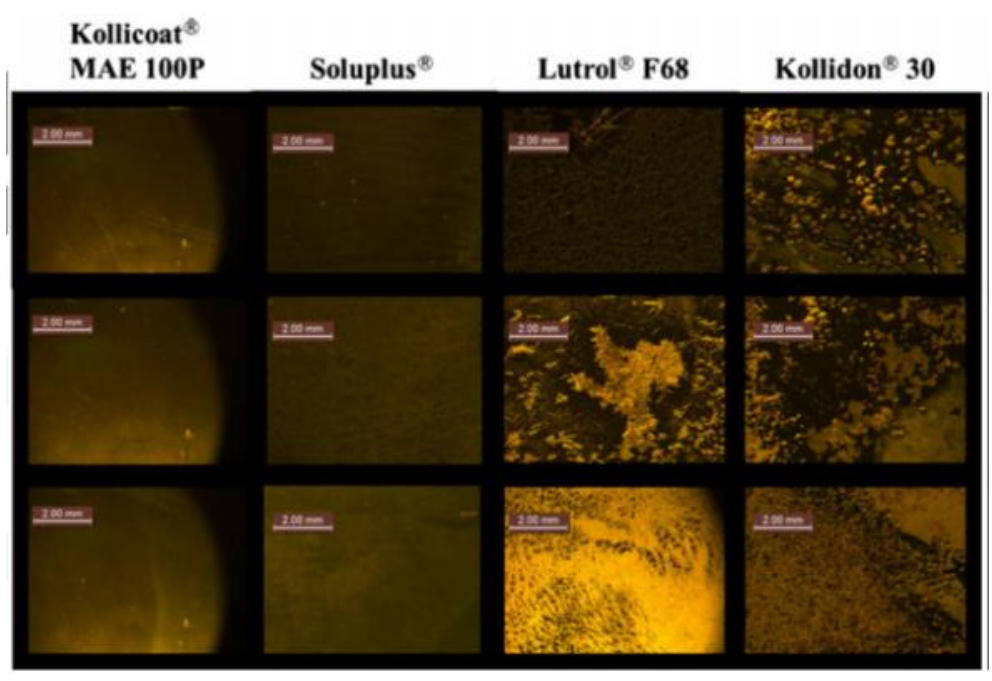

Figure 3. Polarized microscopic view of dutasteride solid dispersion (39)

Parikh et al. use PLM to detect the presence of itraconazole crystals dispersed in Soluplus ${ }^{\circledR}$. The resulting polarization images show the presence of microcrystals birefringence that was not previously detected by DSC and XRD. It should be noted that the presence of microcrystals is also influenced by the ratio between API-polymers. Based on this, PLM is a more sensitive method compared to XRD and DSC for analyzing crystal growth (54). 
M. E. T Butarbutar et al / Indo J Pharm 1 (2020) 55-68

Table 2. Solid-state analytical techniques used to study ASDs

\begin{tabular}{|c|c|c|c|c|c|c|c|c|c|c|c|c|c|c|c|c|c|c|c|c|}
\hline \multirow{3}{*}{ API / Sample } & \multirow[b]{3}{*}{$\begin{array}{l}\text { Processing method } \\
\quad \text { (s) }\end{array}$} & \multicolumn{19}{|c|}{ Solid state analytical technique (s) } \\
\hline & & \multicolumn{4}{|c|}{ Spectroscopy } & \multicolumn{5}{|c|}{ Microscopy } & \multirow{2}{*}{ X-Ray } & \multicolumn{4}{|c|}{$\begin{array}{l}\text { Thermal and } \\
\text { Gravimetric }\end{array}$} & \multicolumn{3}{|c|}{ Others } & \multirow[b]{2}{*}{$\begin{array}{c}\text { Year of } \\
\text { publication }\end{array}$} & \multirow[b]{2}{*}{ Ref } \\
\hline & & 刍 & 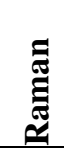 & $\frac{n}{3}$ & $\sum_{\mathscr{V}}^{\mathscr{y}}$ & $\underline{\Sigma}$ & $\sum_{\sqrt[c]{5}}$ & 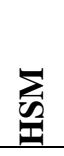 & $\sum_{i}$ & 方 & & Ø̊ & 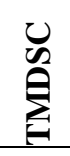 & 岕 & 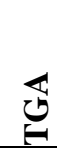 & జ̂. & 它 & : & & \\
\hline Aprepitant & Spray drying & $\sqrt{ }$ & $\sqrt{ }$ & & & $\sqrt{ }$ & & & & & & $\sqrt{ }$ & & & & & & & 2016 & (40) \\
\hline Amphotericin B & Spray drying & $\sqrt{ }$ & $\sqrt{ }$ & $\sqrt{ }$ & & & $\sqrt{ }$ & & & & & $\sqrt{ }$ & & & $\sqrt{ }$ & & & & 2018 & (20) \\
\hline Aripiprazole & Hot Melt Extrusion & & & & & & & & & & $\sqrt{ }$ & $\sqrt{ }$ & & & & & & & 2019 & (41) \\
\hline Atorvastatin & Solvent evaporation & & & & & & $\sqrt{ }$ & & & & $\sqrt{ }$ & $\sqrt{ }$ & & & & & & & 2018 & $(42)$ \\
\hline Betulinic acid & Gently grinding & $\sqrt{ }$ & & & & & $\sqrt{ }$ & & & & $\sqrt{ }$ & & $\sqrt{ }$ & & & & & & 2015 & (43) \\
\hline Bicalutamide & Fusion method & & $\sqrt{ }$ & $\sqrt{ }$ & & $\sqrt{ }$ & & & & & $\sqrt{ }$ & & & & & & $\sqrt{ }$ & & 2015 & (44) \\
\hline Carbamazepine & Hot Melt Extrusion & $\sqrt{ }$ & & & & & & & & & $\sqrt{ }$ & $\sqrt{ }$ & & & $\sqrt{ }$ & & & & 2015 & (45) \\
\hline Carvedilol & Supercritical CO & $\sqrt{ }$ & & & & & $\sqrt{ }$ & & & & $\sqrt{ }$ & & & & $\sqrt{ }$ & & & & 2019 & $(22)$ \\
\hline Cyclosporine & Spray drying & & & $\sqrt{ }$ & $\sqrt{ }$ & & $\sqrt{ }$ & & & & $\sqrt{ }$ & & & & & & & $\sqrt{ }$ & 2018 & (36) \\
\hline Darunavir & Electrospraying & & & & & & $\sqrt{ }$ & & & & $\sqrt{ }$ & & & & & & & & 2018 & (46) \\
\hline Griseofulvin & Melt-quench method & & & & & & & & & & $\sqrt{ }$ & & & & & & $\sqrt{ }$ & & 2019 & (24) \\
\hline Hydrocortisone & Spray drying & $\sqrt{ }$ & & & & & $\sqrt{ }$ & & & & $\sqrt{ }$ & $\sqrt{ }$ & & & & & & & 2019 & $(25)$ \\
\hline Itraconazole & Hot Melt Extrusion & $\sqrt{ }$ & & & & & $\sqrt{ }$ & & & & $\sqrt{ }$ & $\sqrt{ }$ & & & & & & & 2017 & $(47)$ \\
\hline Lapatinib & Solvent evaporation & & & & & & $\sqrt{ }$ & & & & $\sqrt{ }$ & $\sqrt{ }$ & & & & & $\sqrt{ }$ & & 2018 & $(48)$ \\
\hline Lopinavir & Solvent evaporation & $\sqrt{ }$ & & & & & & & & & & $\sqrt{ }$ & & & & & & & 2018 & (49) \\
\hline Leflunomide & Freeze drying & $\sqrt{ }$ & & & & & & & & & $\sqrt{ }$ & $\sqrt{ }$ & & & & & & & 2017 & $(50)$ \\
\hline Nifedipine & Hot Melt Extrusion & & & $\sqrt{ }$ & $\sqrt{ }$ & & & & & & $\sqrt{ }$ & $\sqrt{ }$ & $\sqrt{ }$ & & & & & & 2019 & (15) \\
\hline Nimodipine & Hot Melt Extrusion & $\sqrt{ }$ & & & & & $\sqrt{ }$ & $\sqrt{ }$ & & & $\sqrt{ }$ & $\sqrt{ }$ & & & $\sqrt{ }$ & & & & 2018 & $(51)$ \\
\hline Nitrendipine & Solvent evaporation & $\sqrt{ }$ & $\sqrt{ }$ & & & & & & & $\sqrt{ }$ & & & & & & & & & 2017 & $(31)$ \\
\hline Pyrimethamine & Solvent evaporation & $\sqrt{ }$ & & & $\sqrt{ }$ & & & & & & $\sqrt{ }$ & $\sqrt{ }$ & & & & & & & 2018 & $(27)$ \\
\hline Ritonavir & Solvent evaporation & $\sqrt{ }$ & & & & & $\sqrt{ }$ & $\sqrt{ }$ & & & & & & & & & & & 2019 & $(52)$ \\
\hline Tadalafil & Spray drying & & & & & & $\sqrt{ }$ & $\sqrt{ }$ & $\sqrt{ }$ & & $\sqrt{ }$ & $\sqrt{ }$ & & & $\sqrt{ }$ & & $\sqrt{ }$ & & 2015 & $(53)$ \\
\hline
\end{tabular}


Unlike HSPLM which can visually determine the melting and thermal transition levels. The HSPLM application is used against the ASDs nifedipine-PVP which demonstrates the visualization differences between ASDs nifedipine and crystalline nifedipine prior to melting, the onset of melting, when melted, and after melting perfectly. HSPLM provides information that the transformation of crystal form into amorphous form (15).

\section{SEM}

SEM has been widely used in the pharmaceutical field to develop and control the quality of materials and dose. The main purpose of using SEM is to analyze the morphology of the sample, particle size, and formulation so that it can be used to analyze ASDs. Quantitative analysis can also be obtained
(55). The electrons in the SEM interact with the sample resulting in a complex signaling mechanism. Specimen interaction with electrons can be classified into two groups, i.e. elastic and non-elastic collision. Elastic collision occurs when electrons strike the specimen and change the direction without losing energy. Whereas non-elastic collision does not change direction, but transfers the electrons to the specimen (56).

Das et al. used SEM to characterize the morphology of pure ibuprofen and ASDs ibuprofencaptisol $^{\circledR}$ (Fig. 4) The morphology of ibuprofen was shown as rectangular crystals with a smooth surface while the morphology of captisol ${ }^{\circledR}$ was spherical. The morphology of ASDs ibuprofen changed with the loss of rectangular shape (57).
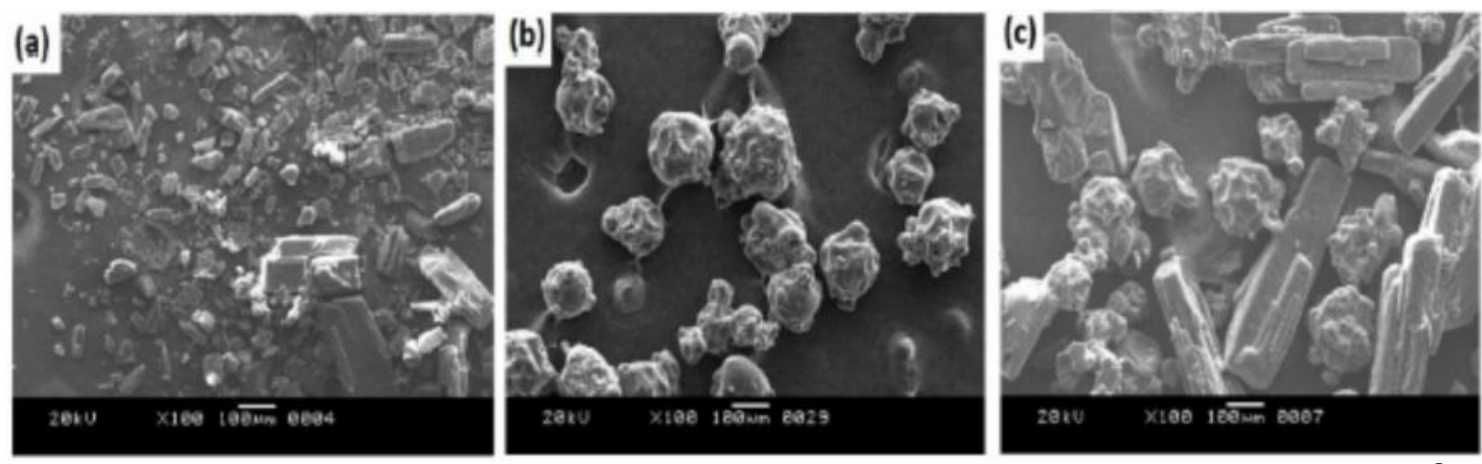

Figure 4. Scanning electron micrograph (a) Ibuprofen, (b) Captisol, (c) Ibuprofen-Captisol ${ }^{\circledR}$ (58)

The use of SEM was also carried out by Ha et al. to analyze celecoxib-PVP K30 ASDs. The used nano-size particles were dispersible in PVP K30. ASDs celecoxib-PVP K30 were spherical nanoparticles with particle sizes ranging from $150-$ $158 \mathrm{~nm}$ and surface area from $78-81 \mathrm{~m}^{2} / \mathrm{g}$. SEM results showed that the morphology of ASDs celecoxib did not differ significantly from pure celecoxib. However, particle size and surface area differed significantly. This was influenced by the addition of surfactants (59).

\subsubsection{X-Ray Diffraction}

$\mathrm{XRD}$ is an analytical method that can show specific molecular materials such as crystals, mesophases, amorphous, and mixtures. Not only in the form of powder, now XRD can also analyze intact tablet preparations (60). The appearance of the diffraction peak indicates the crystalline molecule, whereas the absence of the diffraction peak indicates that the molecule is amorphous (61). The information gathered is in the form of a diffractogram consisting of intensity and an angle of 20. XRD application is widely used to study the kinetics of crystallization in solid dispersion systems. Many factors also influence the diffractogram, including the temperature of the treatment and the method of manufacture. Examples of applications using XRD, the kinetics of crystallization of ASDs naproxen-polyethylene glycol reduced compared to pure naproxen which was affected by temperature differences. At the temperature of $25{ }^{\circ} \mathrm{C}$, naproxen crystallizes faster 
than at $40{ }^{\circ} \mathrm{C}$. However, the addition of polyethylene glycol can slow the crystallization that happened at $40{ }^{\circ} \mathrm{C}$. Additionally the addition of polyethylene glycol results in a smaller naproxen domain in the matrix. In addition, other studies conducted by Surana et al. compared crystallization kinetics based on amorphous manufacturing methods, i.e. the method of melt quenching, spray drying, freeze drying, and dehydration of trehalose dihydrate. The results of the study found that the dehydration of trehalose dihydrate had the fastest crystallization. This was caused by differences in molecular nucleic. In this study it can be concluded that there are significant differences from each method on the results of the XRD analysis (62).

Homayouni et al. also performed celecoxib-PVPK30 ASDs analysis. Pure celecoxib diffraction showed the formation of the crystal presented by the sharp peaks at a value of $2 \theta$ at $5^{\circ} ; 10.5^{\circ} ; 16^{\circ}$; and $21.5^{\circ}$ (Fig. 5).

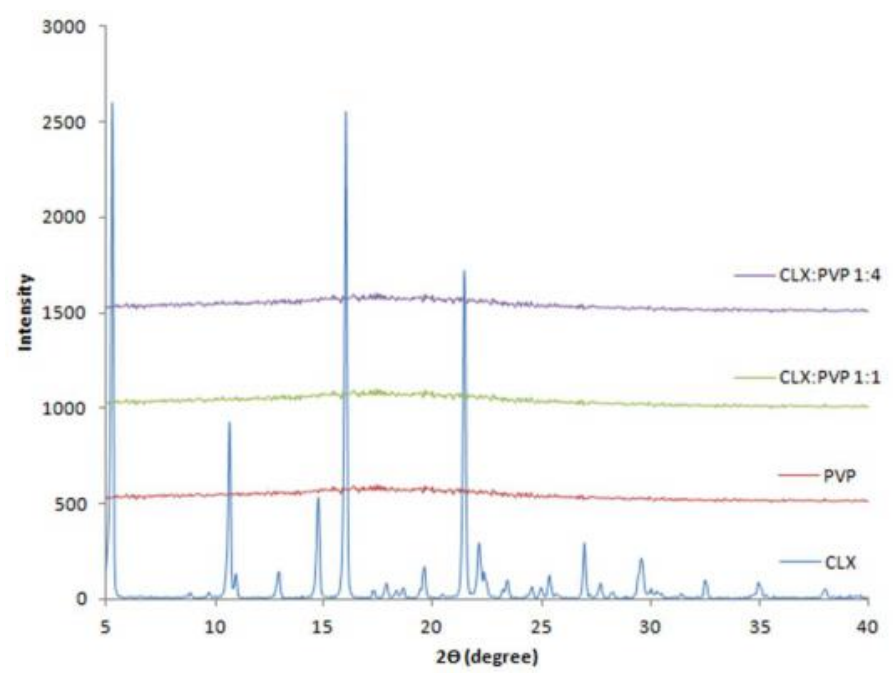

Figure 5. X-ray powder diffractions of pue celecoxib (CLX), polyvinylpyrrolidone K-30 (PVP) and CLX : PVP K-30 (63).

Whereas, PVP-K30 showed amorphous nature due to the absence of diffraction peaks. In a solid dispersion system using the solvent evaporation method, ASDs celecoxib-PVP-K30 did not find diffraction peaks. This indicates that celecoxib crystals have been converted to amorphous in a solid dispersion system (61).
To this date, XRD is one of the most popular methods of analyzing ASDs because it provides very informative results regarding the conversion of crystals to amorphous, and vice versa.

\subsubsection{Thermal Analysis}

Thermal analysis is used to study the properties of materials affected by temperature. Information that can be obtained, such as glass transition $\left(T_{\mathrm{g}}\right)$, melting temperature $\left(T_{\mathrm{m}}\right)$, decomposition temperature $\left(T_{\mathrm{d}}\right)$, crystallization temperature $\left(T_{\mathrm{c}}\right)$, transformation polymorphism, crystallization, desolvation, entalphi value, and changes in chemical reactions in the form of endothermic reactions (heat absorption) or exothermic (heat release) (64). The occurrence of $T_{\mathrm{m}}$ indicates the characteristics of a solid that is changing enthalpy, such as crystal solids, whereas $T_{\mathrm{g}}$ indicated amorphous because it is considered as a point of transition (65). Looking at ASDs consisting of complex components (API and polymer) allows interactions that affect the thermodynamic nature of the drug. The methods included in thermal analysis are DSC, TMDSC, DTA, and TGA, information obtained is in the form of a thermo gram that describes the thermal characteristics of the sample being analyzed.

\section{DSC and TMDSC}

DSC and TMDSC methods that can analyze up to the molecular level. However, DSC has a disadvantage, that is, thermogram interpretation can be hindered if two or more thermal events overlap. Unlike the case with TMDSC, fast-scans on very sensitive TMDSC can separate complex overlapping thermal events. TMDSC can also detect glass transition temperatures and amorphous phase quantification accurately, and the availability of relaxation time calculations when phase separation occurs. But will, the downside of these thermal analysis results is that it cannot accurately analyze the events that occur concurrently and will result in overlap (56).

In ASDs, drug mixtures with polymers must be soluble and homogeneous because they affect the thermodynamic profile. It is expected that ASDs have high $T_{\mathrm{g}}$ and low enthalpy so that they are 
physically stable. Wlodarski et al. to see the thermodynamic properties of ASDs tadalafilPVPVA using spray drying method. DSC provided information on $T_{\mathrm{g}}$ of crystalline tadalafil on $149.9^{\circ} \mathrm{C}$ followed by an exothermic reaction with an onset of $181.6{ }^{\circ} \mathrm{C}$ and $\mathrm{Tm}$ of endothermic reaction is shown at peak on $302.1{ }^{\circ} \mathrm{C}$ (Fig. 6).

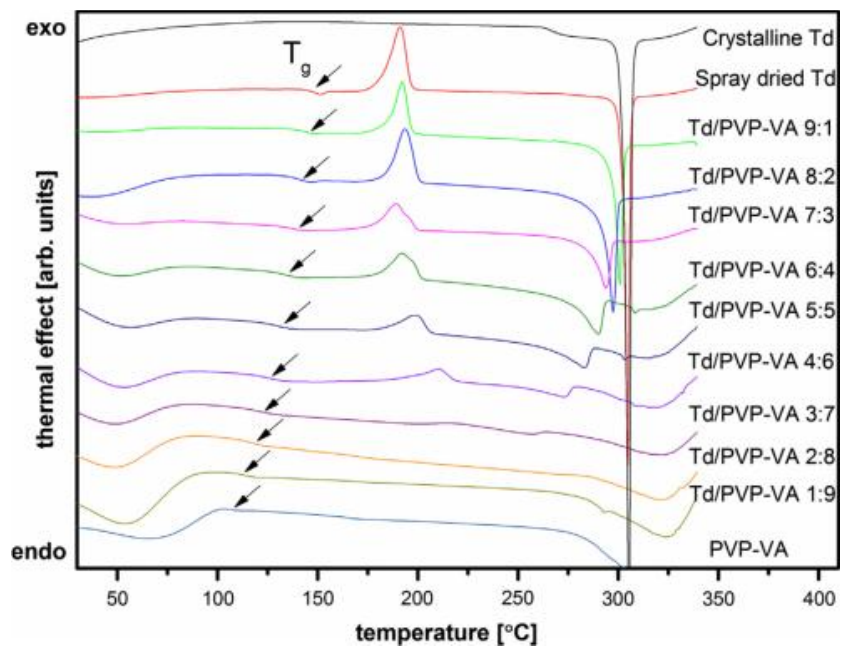

Figure 6. DSC thermograms (from top to bottom) crystalline tadalafil (Td), spray dried tadalafil, 9:1 1:9 (w/w) Td-PVPVA solid dispersion (66).

In a solid dispersion system, the peak endothermic reaction experienced a change in $T_{\mathrm{m}}$ under the endothermic reaction of crystalline tadalafil amorphous molecular enthalpy relaxation usually occurs around $T_{\mathrm{g}}(67)$.

In its application the concentration of API: polymer contributes to $T_{\mathrm{g}}$, such as $T_{\mathrm{g}}$ betulinic acid $188.81^{\circ} \mathrm{C}, T_{\mathrm{g}}$ 74.25. In solid dispersion systems with a ratio of $1: 4 T_{\mathrm{g}}$ ASDs to $77.45^{\circ} \mathrm{C}$. This $T_{\mathrm{g}}$ value also affects the solubility of betulinic acid ASDs which increases 15-fold (43). From this example it can be concluded that the polymer can increase $T_{\mathrm{g}}$ of API and slow down the mobility of amorphous molecules as well as inhibit the crystallization process.

\section{TGA}

TGA is generally combined with other methods, such as DSC and FTIR. In the characterization of ASDs, TGA is used to determine thermal stability, changes in material weight affected by temperature, decomposition, the profile of volatile components. It is important to note the thermal characteristics of each component to determine the temperature range used in TGA applications. Research conducted by Mehenni et al., Using TGA with a temperature range of $30-150^{\circ} \mathrm{C}$. amphotericin B $3.40 \%$, poly $\gamma$-CD $5.69 \%$, while the dispersion system experienced an weight loss of $1.87 \%$, which is the percentage of evaporation of water that depends on relative humidity. This percentage decrease indicates that there is an interaction between amphotericin B and poly $\gamma$-CD (20). Aripiprazole ASDs prepared by the hot melt extrusion method using PVP experienced a weight loss of 5\% (Fig. 7).

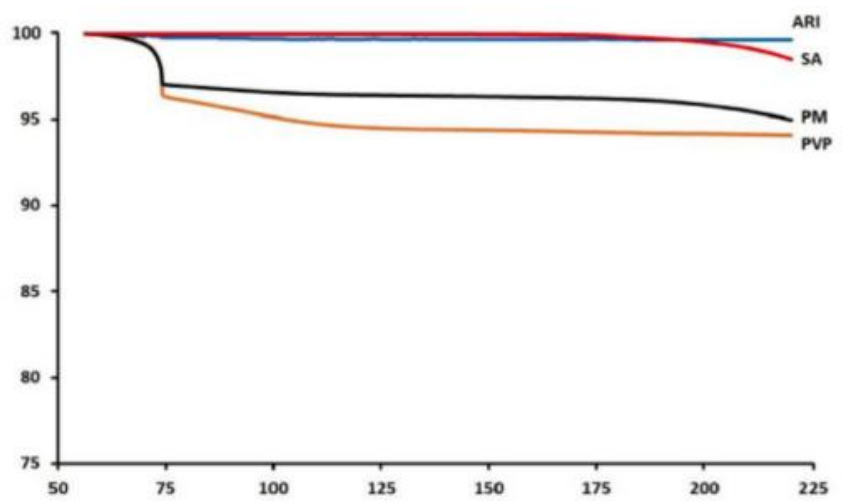

Figure 7. Thermogravimetric curves of Aripiprazole (ARP), succinic acid (SA), physical mixture (PM), and polyvinylpyrrolidone (PVP) (41).

Because PVP is highly hydrophilic which contains about $5 \%$ water, when affected by temperatures of $60-220{ }^{\circ} \mathrm{C}$ the water is evaporated (41). In terms of the results obtained, the TGA does not provide specific information regarding the state of the amorphous form in solid dispersions.

\subsection{Products of Amorphous Solid Dispersion}

Amorphous in the solid dispersion system has demonstrated its success in overcoming the solubility of poorly water soluble drugs and the method of solid dispersion in maintaining amorphous stability. Therefore, the FDA has approved several ASDs products that have been circulating in the market, among which are presented in Table 3. 
Table 3. Amorphous solid dispersion products on the market $(9,68)$

\begin{tabular}{|c|c|c|c|c|c|c|}
\hline API & BCS & Indication & Polymer & $\begin{array}{c}\text { Preparation } \\
\text { method }\end{array}$ & Product & $\begin{array}{r}\text { Year of } \\
\text { acc. }\end{array}$ \\
\hline Nabilone & IV & Antiemetic & PVP & - & $\begin{array}{c}\text { Cesamet } \\
\text { TM }\end{array}$ & 1985 \\
\hline Itroconazole & II & Antifungal & HPMC & Spray drying & Sporanox ${ }^{\circledR}$ & 1992 \\
\hline Tacrolimus & II & immunosuppressive & HPMC & Spray drying & Prograf TM & 1994 \\
\hline Griseofluvin & II & Antigungal & PEG & Melt extruction & $\begin{array}{c}\text { Gris-PEG } \\
\text { TM }\end{array}$ & 2000 \\
\hline Lopinavir & IV & Antiretroviral & PVP-VA & Melt extruction & Kaletra $^{\circledR}$ & 2005 \\
\hline Etravirine & IV & Antiretroviral & HPMC & Spray drying & Intelence ${ }^{\circledR}$ & 2008 \\
\hline Ritonavir & IV & Antiretroviral & PVP-PA & Melt extruction & Novir $^{\circledR}$ & 2010 \\
\hline Ivacaftor & II & Cystic fibrosis & HPMCAS & Spray drying & Kalydeco ${ }^{\circledR}$ & 2010 \\
\hline Everolimus & IV & immunosuppressive & HPMC & Spray drying & Zotress $^{\circledR}$ & 2010 \\
\hline Itroconazole & II & Antifungal & HPMC & Melt extruction & Onmel $^{\circledR}$ & 2010 \\
\hline Fenofibrate & II & Hypercholesterolemia & $\begin{array}{c}\text { PEG/Poloxamer } \\
188\end{array}$ & Spray melt & Fenoglide & 2010 \\
\hline Telaprevir & II & Antiviral & HPMCAS & Spray drying & Incivek $^{\circledR}$ & 2011 \\
\hline Vemurafenib & IV & Melanoma & HPMCAS & Coprecipitation & Zelboraf $^{\circledR}$ & 2011 \\
\hline Posaconazole & II & Antifungal & HPMCAS & Melt extruction & Noxafil $^{\circledR}$ & 2013 \\
\hline Ombitasvir & IV & Antiviral & PVP-VA/TPGS & Melt extruction & Viekirax ${ }^{\circledR}$ & 2014 \\
\hline Lumacaftor & II & Cystic fibrosis & HPMCAS & Spray drying & Orkambi ${ }^{\circledR}$ & 2015 \\
\hline
\end{tabular}

So far there have been $>15$ ASDs products circulated in the market. Among them, tacrolimus prepared by spray drying method using HPMC showed an increase in solubility of 25 fold, $\mathrm{C}_{\max } 10$ fold, and AUC 9.9 fold of crystal for. Ziprasiode hydrochloride prepared by merely mixing HPMCAS showed an increase of 1.5 fold solubility of the crystal form. Additionaly, CAPHth / itaconazole ASDs show a 2 fold increase in biovailability of the crystal form (69). Many ASDs have demonstrated success in increasing the solubility, dissolution rate, and bioavailability of previous products. Considering the advantages and potential offered by ASDs with more efficient therapeutic products, it is not that surprising there are currently many researches focused on ASDs.

\section{Conclusion}

Amorphous API forms dispersed in hydrophilic polymer have shown success in increasing solubility. Each ASDs preparation method must take notice to the thermal and solubility characteristics of API and polymer. Hot melt extrusion is a preparation method that is widely used because it does not cause residues and has produced good quality ASDs. Because of its molecular nature, ASDs evaluated for detecting amorphous stability using various methods such as PLM which is very sensitive to the presence of microcrystals, XRD with no peaks in the diffractogram that indicate amorphous form, and DSC to changes in the thermal characteristic components of ASDs. Reviewing the success of ASDs from the increase in solubility, dissolution rate, and bioavailability of previous products, currently as many as $>15$ patent products have been circulating in the market and become promising products in the future.

\section{Acknowledgements}

Author would like to thank lecturer Dr. Yoga Windhu Wardhana, M. Si., Apt. and Nasrul Wathoni, Ph.D., Apt. for his guidance and support for the drafting of this article. 


\section{References}

1. Williams HD, Trevaskis NL, Charman SA, Shanker RM, Charman WN, Pouton CW, et al. Strategies to address low drug solubility in discovery and development. Pharmacol Rev. 2013;65(1):315-499.

2. $\mathrm{Ku} \mathrm{MS}$, Dulin W. A biopharmaceutical classification-based Right-First-Time formulation approach to reduce human pharmacokinetic variability and project cycle time from First-In-Human to clinical Proof-OfConcept. Pharm Dev Technol. 2012;17(3):285302.

3. Di L, Fish P V., Mano T. Bridging solubility between drug discovery and development. Drug Discov Today. 2012;17(9-10):486-95.

4. Khadka P, Ro J, Kim H, Kim I, Kim JT, Kim H, et al. Pharmaceutical particle technologies: An approach to improve drug solubility, dissolution and bioavailability. Asian J Pharm Sci. 2014;9(6):304-16.

5. Sachin Parmar, Amit Gangwal NSD.Scholar.Scholars Research Library. 2011;2(4):373-83.

6. Mansour RSH, Deb PK, Tekade RK. Role of Amorphous State in Drug Delivery. Dosage Form Design Parameters. 2018. 105-154 p.

7. He Y, Ho C. Amorphous Solid Dispersions: Utilization and Challenges in Drug Discovery and Development. J Pharm Sci. 2015;104(10):3237-58.

8. Kumar DP, Dispersions S, Kumar DP, Vandana A. Journal of Pharmaceutical and Scientific Innovation SOLID DISPERSIONS : A REVIEW. 2012;1(June):27-34.

9. Jermain $\mathrm{S}$ V., Brough $\mathrm{C}$, Williams RO. Amorphous solid dispersions and nanocrystal technologies for poorly water-soluble drug delivery - An update. Int J Pharm. 2018;535(12):379-92.

10. Baghel S, Cathcart H, O'Reilly NJ. Theoretical and experimental investigation of drug-polymer interaction and miscibility and its impact on drug supersaturation in aqueous medium. Eur $\mathbf{J}$ Pharm Biopharm. 2016;107:16-31. Available from:
11. Mazumder S, Dewangan AK, Pavurala N. Enhanced dissolution of poorly soluble antiviral drugs from nanoparticles of cellulose acetate based solid dispersion matrices. Asian J Pharm Sci. 2017;12(6):532-41.

12. Sathigari SK, Radhakrishnan VK, Davis VA, Parsons DL, Babu RJ. Amorphous-state characterization of efavirenz-polymer hot-melt extrusion systems for dissolution enhancement. J Pharm Sci. 2012;101(9):3456-64.

13. Gao N, Guo M, Fu Q, He Z. Application of hot melt extrusion to enhance the dissolution and oral bioavailability of oleanolic acid. Asian $\mathbf{J}$ Pharm Sci. 2017;12(1):66-72.

14. Herbrink M, Schellens JHM, Beijnen JH, Nuijen B. Improving the solubility of nilotinib through novel spray-dried solid dispersions. Int J Pharm. 2017;529(1-2):294-302.

15. Ma X, Huang S, Lowinger MB, Liu X, Lu X, Su $Y$, et al. Influence of mechanical and thermal energy on nifedipine amorphous solid dispersions prepared by hot melt extrusion: Preparation and physical stability. Int J Pharm. 2019;561:324-34.

16. Van Drooge DJ, Hinrichs WLJ, Visser MR, Frijlink HW. Characterization of the molecular distribution of drugs in glassy solid dispersions at the nano-meter scale, using differential scanning calorimetry and gravimetric water vapour sorption techniques. Int $\mathrm{J}$ Pharm. 2006;310(1-2):220-9.

17. Paudel A, Worku ZA, Meeus J, Guns S, Van Den Mooter G. Manufacturing of solid dispersions of poorly water soluble drugs by spray drying: Formulation and process considerations. Int J Pharm. 2013;453(1):25384.

18. Shah S, Maddineni S, Lu J, Repka MA. Melt extrusion with poorly soluble drugs. Int $\mathbf{J}$ Pharm. 2013;453(1):233-52.

19. Tran P, Pyo Y-C, Kim D-H, Lee S-E, Kim J-K, Park J-S. Overview of the Manufacturing Methods of Solid Dispersion Technology for Improving the Solubility of Poorly WaterSoluble Drugs and Application to Anticancer Drugs. Pharmaceutics. 2019;11(3):132. 
20. Mehenni L, Lahiani-Skiba M, Ladam G, Hallouard F, Skiba M. Preparation and Characterization of Spherical Amorphous Solid Dispersion with Amphotericin B. Pharmaceutics. 2018;10(4):235.

21. Li Y, He ZD, Zheng QE, Hu C, Lai WF. Hydroxypropyl- $\beta$-cyclodextrin for delivery of baicalin via inclusion complexation by supercritical fluid encapsulation. Molecules. 2018;23(5).

22. Milovanovic S, Djuris J, Dapčević A, Medarevic D, Ibric S, Zizovic I. Soluplus ${ }^{\circledR}$, Eudragit ${ }^{\circledR}$, HPMC-AS foams and solid dispersions for enhancement of Carvedilol dissolution rate prepared by a supercritical $\mathrm{CO}_{2}$ process. Vol. 76, Polymer Testing. Elsevier Ltd; 2019. 54-64 p.

23. Lu J, Cuellar K, Hammer NI, Jo S, Gryczke A, Kolter K, et al. Solid-state characterization of Felodipine-Soluplus amorphous solid dispersions. Drug Dev Ind Pharm. 2016;42(3):485-96.

24. Zheng K, Lin Z, Capece M, Kunnath K, Chen L, Davé RN. Effect of Particle Size and Polymer Loading on Dissolution Behavior of Amorphous Griseofulvin Powder. J Pharm Sci. 2019;108(1):234-42.

25. Altamimi MA, Elzayat EM, Qamar W, Alshehri SM, Sherif AY, Haq N, et al. Evaluation of the bioavailability of hydrocortisone when prepared as solid dispersion. Saudi Pharm J. 2019;

26. Ziaee A, O'Dea S, Howard-Hildige A, Padrela L, Potter C, Iqbal J, et al. Amorphous solid dispersion of ibuprofen: A comparative study on the effect of solution based techniques. Int J Pharm. 2019;118816.

27. Khatri P, Shah MK, Patel N, Jain S, Vora N, Lin $S$. Preparation and characterization of pyrimethamine solid dispersions and an evaluation of the physical nature of pyrimethamine in solid dispersions. J Drug Deliv Sci Technol. 2018;45:110-23.

28. Indulkar AS, Lou X, Zhang GGZ, Taylor LS. Insights into the Dissolution Mechanism of Ritonavir-Copovidone Amorphous Solid Dispersions: Importance of Congruent Release for Enhanced Performance. Vol. 16, Molecular Pharmaceutics. 2019. 1327-1339 p.

29. Milne M, Liebenberg W, Aucamp M. The Stabilization of Amorphous Zopiclone in an Amorphous Solid Dispersion. AAPS PharmSciTech. 2015;16(5):1190-202.

30. Ma X, Williams RO. Characterization of amorphous solid dispersions: An update. J Drug Deliv Sci Technol. 2019;50(November 2018):113-24.

31. Li J, Fan N, Li C, Wang J, Li S, He Z. The tracking of interfacial interaction of amorphous solid dispersions formed by water-soluble polymer and nitrendipine. Appl Surf Sci. 2017;420:136-44.

32. Lust A, Strachan CJ, Veski P, Aaltonen J, Heinämäki J, Yliruusi J, et al. Amorphous solid dispersions of piroxicam and Soluplus ${ }^{\circledR}$ : Qualitative and quantitative analysis of piroxicam recrystallization during storage. Int $\mathbf{J}$ Pharm. 2015;486(1-2):306-14.

33. Paudel A, Geppi M, Van Den Mooter G. Structural and dynamic properties of amorphous solid dispersions: The role of solid-state nuclear magnetic resonance spectroscopy and relaxometry. J Pharm Sci. 2014;103(9):263562.

34. Yuan X, Sperger D, Munson EJ. Investigating miscibility and molecular mobility of nifedipine-PVP amorphous solid dispersions using solid-state NMR spectroscopy. Mol Pharm. 2014;11(1):329-37.

35. Tombari E, Ferrari C, Johari GP, Shanker RM. Calorimetric relaxation in pharmaceutical molecular glasses and its utility in understanding their stability against crystallization. J Phys Chem B. 2008;112(35):10806-14.

36. Lahiani-Skiba M, Hallouard F, Bounoure F, Milon N, Karrout Y, Skiba M. Enhanced Dissolution and Oral Bioavailability of Cyclosporine A: Microspheres Based on $\alpha \beta$ Cyclodextrins Polymers. Pharmaceutics. 2018;10(4):285.

37. Guo Y, Shalaev E, Smith S. Physical stability of pharmaceutical formulations: Solid-state 
characterization of amorphous dispersions. TrAC - Trends Anal Chem. 2013;49:137-44.

38. Li Y, Pang H, Guo Z, Lin L, Dong Y, Li G, et al. Interactions between drugs and polymers influencing hot melt extrusion. J Pharm Pharmacol. 2014;66(2):148-66.

39. Kim NA, Choi DH, Lim JY, Kim KH, Lim DG, Lee $\mathrm{E}$, et al. Investigation of polymeric excipients for dutasteride solid dispersion and its physicochemical characterization. Arch Pharm Res. 2014;37(2):214-24.

40. Punčochová K, Ewing A V., Gajdošová M, Pekárek T, Beránek J, Kazarian SG, et al. The Combined Use of Imaging Approaches to Assess Drug Release from Multicomponent Solid Dispersions. Pharm Res. 2017;34(5):9901001.

41. McFall H, Sarabu S, Shankar V, Bandari S, Murthy SN, Kolter K, et al. Formulation of aripiprazole-loaded $\mathrm{pH}$-modulated solid dispersions via hot-melt extrusion technology: In vitro and in vivo studies. Int $\mathbf{J}$ Pharm. 2019;554(June 2018):302-11.

42. Dong W, Su X, Xu M, Hu M, Sun Y, Zhang P. Preparation, characterization, and in vitro/vivo evaluation of polymer-assisting formulation of atorvastatin calcium based on solid dispersion technique. Asian J Pharm Sci. 2018;13(6):54654.

43. Yu M, Ocando JE, Trombetta L, Chatterjee P. Molecular Interaction Studies of Amorphous Solid Dispersions of the Antimelanoma Agent Betulinic Acid. AAPS PharmSciTech. 2015;16(2):384-97.

44. Tres F, Coombes SR, Phillips AR, Hughes LP, Wren SAC, Aylott JW, et al. Investigating the dissolution performance of amorphous solid dispersions using magnetic resonance imaging and proton NMR. Molecules. 2015;20(9):16404-18.

45. Alshahrani SM, Lu W, Park J-B, Morott JT, Alsulays BB, Majumdar S, et al. Stabilityenhanced Hot-melt Extruded Amorphous Solid Dispersions via Combinations of Soluplus ${ }^{\circledR}$ and HPMCAS-HF. AAPS PharmSciTech. 2015;16(4):824-34.
46. Smeets A, Koekoekx R, Clasen C, Van den Mooter G. Amorphous solid dispersions of darunavir: Comparison between spray drying and electrospraying. Eur J Pharm Biopharm. 2018;130:96-107.

47. Albadarin AB, Potter CB, Davis MT, Iqbal J, Korde S, Pagire S, et al. Development of stability-enhanced ternary solid dispersions via combinations of HPMCP and Soluplus ${ }^{\circledR}$ processed by hot melt extrusion. Int J Pharm. 2017;532(1):603-11.

48. $\mathrm{Hu} \mathrm{XY}$, Lou H, Hageman MJ. Preparation of lapatinib ditosylate solid dispersions using solvent rotary evaporation and hot melt extrusion for solubility and dissolution enhancement. Int J Pharm. 2018;552(1-2):15463.

49. Li N, Taylor LS. Tailoring supersaturation from amorphous solid dispersions. J Control Release. 2018;279:114-25.

50. Volkova T V., Perlovich GL, Terekhova I V. Enhancement of dissolution behavior of antiarthritic drug leflunomide using solid dispersion methods. Thermochim Acta. 2017;656:123-8.

51. Zhang Q, Zhao Y, Zhao Y, Ding Z, Fan Z, Zhang $\mathrm{H}$, et al. Effect of HPMCAS on recrystallization inhibition of nimodipine solid dispersions prepared by hot-melt extrusion and dissolution enhancement of nimodipine tablets. Colloids Surfaces B Biointerfaces. 2018;172(May):118-26.

52. Indulkar AS, Lou X, Zhang GGZ, Taylor LS. Insights into the Dissolution Mechanism of Ritonavir-Copovidone Amorphous Solid Dispersions: Importance of Congruent Release for Enhanced Performance. Vol. 16, Molecular Pharmaceutics. 2019. 1327-1339 p.

53. Wlodarski K, Sawicki W, Kozyra A, Tajber L. Physical stability of solid dispersions with respect to thermodynamic solubility of tadalafil in PVP-VA. Eur J Pharm Biopharm. 2015;96(August):237-46.

54. Parikh T, Gupta SS, Meena AK, Vitez I, Mahajan N, Serajuddin ATM. Application of Film-Casting Technique to Investigate Drug- 
Polymer Miscibility in Solid Dispersion and Hot-Melt Extrudate. J Pharm Sci. 2015;104(7):2142-52.

55. Brandl M, Frank K, Westedt, Rosenblatt, Hölig, Rosenberg, et al. The amorphous solid dispersion of the poorly soluble ABT-102 forms nano/microparticulate structures in aqueous medium: impact on solubility. Int $\mathbf{J}$ Nanomedicine. 2012;5757.

56. Ma X, Williams RO. Characterization of amorphous solid dispersions: An update. J Drug Deliv Sci Technol. 2019;50:113-24.

57. Das SK, Kahali N, Bose A, Khanam J. Physicochemical characterization and in vitro dissolution performance of ibuprofen-Captisol ${ }^{\circledR}$ (sulfobutylether sodium salt of $\beta$-CD) inclusion complexes. J Mol Liq. 2018;261(2017):239-49.

58. Das SK, Kahali N, Bose A, Khanam J. Physicochemical characterization and in vitro dissolution performance of ibuprofen-Captisol ${ }^{\circledR}$ (sulfobutylether sodium salt of $\beta$-CD) inclusion complexes. J Mol Liq. 2018;261(2017):239-49.

59. Ha ES, Choo GH, Baek IH, Kim MS. Formulation, characterization, and in vivo evaluation of celecoxib-PVP solid dispersion nanoparticles using supercritical antisolvent process. Molecules. 2014;19(12):20325-39.

60. Thakral NK, Thakral S, Stephenson GA, Sedlock R, Suryanarayanan R. CompressionInduced Polymorphic Transformation in Tablets: Role of Shear Stress and Development of Mitigation Strategies. J Pharm Sci. 2019;108(1):476-84.

61. Homayouni A, Sadeghi F, Nokhodchi A, Varshosaz J, Afrasiabi Garekani H. Preparation and characterization of celecoxib solid dispersions; comparison of poloxamer-188 and
PVP-K30 as carriers. Iran J Basic Med Sci. 2014;17(5):322-31.

62. Zhu Q, Toth SJ, Simpson GJ, Hsu HY, Taylor LS, Harris MT. Crystallization and dissolution behavior of naproxen/polyethylene glycol solid dispersions. J Phys Chem B. 2013;117(5):1494500.

63. Homayun B, Lin X, Choi H-J. Challenges and Recent Progress in Oral Drug Delivery Systems for Biopharmaceuticals. Pharmaceutics. 2019;11(3):129.

64. Baird JA, Taylor LS. Evaluation of amorphous solid dispersion properties using thermal analysis techniques. Adv Drug Deliv Rev. 2012;64(5):396-421.

65. Jójárt-Laczkovich $\mathrm{O}$. Amorphization of a crystalline active agent with the aim of pharmaceutical technological formulation. 2012.

66. Wlodarski K, Sawicki W, Haber K, Knapik J, Wojnarowska Z, Paluch M, et al. Physicochemical properties of tadalafil solid dispersions - Impact of polymer on the apparent solubility and dissolution rate of tadalafil. Eur $\mathbf{J}$ Pharm Biopharm. 2015;94(May):106-15.

67. Wlodarski K, Sawicki W, Kozyra A, Tajber L. Physical stability of solid dispersions with respect to thermodynamic solubility of tadalafil in PVP-VA. Eur $\mathrm{J}$ Pharm Biopharm. 2015;96(August):237-46.

68. Rams-Baron M, Jachowicz R, Boldyreva E, Zhou D, Jamroz W, Paluch M, et al. Physical Instability: A Key Problem of Amorphous Drugs. Amorphous Drugs. 2018. 107-157 p.

69. Chavan RB, Rathi S, Jyothi VGSS, Shastri NR. Cellulose based polymers in development of amorphous solid dispersions. Asian J Pharm Sci. 2018;248-264. 